\title{
McMaster forms Russell Colloquium
}

The newly formed Advisory Board of the Bertrand Russell Archives has established a Russel1 Colloquium. A forum for new work in Russell studies, the Colloquium will sponsor three kinds of events: workshops in which local and visiting researchers will present their findings; formal lectures (one each term), at which distinguished lecturers will be invited to disclose new interpretations; and occasional symposia, like the one which marked Russell's centenary at McMaster.

The first workshops will be led by Dr. Louis Greenspan, of the Department of Religion. His subject will be "Russell: Science and Liberty". The workshops will be held in Room 311 of Mills Memorial Library at 2-3 p.m., Monday, February 14 and Monday, February 21. A11 are we1come.

The first lecture will be given by Dr. R.A. Rempel of the History Department. His subject will be "Russell's First Crusade: Free Trade and the New Liberalism, 1903-1914". The lecture will be given in Convocation Hall on Thursday, March 17 th, at 8 p.m. Again all are welcome. 